\title{
Impact of light-curing time and aging on dentin bond strength of methacrylate- and silorane- based restorative systems
}

\author{
Anderson Catelan ${ }^{1}$, Giulliana Panfiglio Soares ${ }^{1}$, Ana Karina Bedran-Russo ${ }^{2}$, Débora Alves Nunes Leite Lima ${ }^{1}$, \\ Giselle Maria Marchi', Flávio Henrique Baggio Aguiar ${ }^{1}$
}

${ }^{1}$ Universidade Estadual de Campinas - UNICAMP, Piracicaba Dental School, Department of Restorative Dentistry, Piracicaba, SP, Brazil

${ }^{2}$ University of Illinois at Chicago, College of Dentistry, Department of Restorative Dentistry, Chicago, IL, USA

Received for publication: June 26, 2014 Accepted: September 02, 2014

\section{Correspondence to:}

Anderson Catelan

Departamento de Odontologia Restauradora Faculdade de Odontologia de Piracicaba - UNICAMP

Av. Limeira, 901 Areião, Caixa Postal 52 CEP 13414-903 Piracicaba, SP, Brazil

Phone: +55 1921065337 Fax: +55 1934210144 E-mail: catelan@estadao.com.br

\begin{abstract}
Aim: To evaluate the impact of different light-curing times on dentin microtensile bond strength of two restorative systems after $24 \mathrm{~h}$ and 6 months of water storage. Methods: Standardized Class II preparations were performed in 56 freshly-extracted human molars $(n=7)$, restored with methacrylate- or silorane-based restorative systems, and light-cured using a light-emitting diode at $1390 \mathrm{~mW} / \mathrm{cm}^{2}$ by the recommended manufacturers' time or double this time. After storage for 24 h at $37^{\circ} \mathrm{C}$, the teeth were sectioned to yield a series of $0.8-\mathrm{mm}$ thick slices. Each slab was trimmed into an hourglass shape of approximately $0.64 \mathrm{~mm}^{2}$ area at the gingival dentin-resin interface. Specimens were tested using universal testing machine at crosshead speed of $0.5 \mathrm{~mm} / \mathrm{min}$ until failure, after $24 \mathrm{~h}$ and 6 months of storage. Data were statistically analyzed by three-way ANOVA and Tukey's test $(\alpha=0.05)$. Results: The highest bond strength values were recorded for the groups restored with methacrylate system $(p<0.001)$ as well as for extended light-curing time ( $p$ $=0.0034$ ). There was no statistically significant difference between $24 \mathrm{~h}$ and 6 months storage on bond strength $(p>0.05)$. Conclusions: Bond strength was influenced by the material and lightcuring time, but the 6 -month storage did not affect the bond strength of restorations.
\end{abstract}

Keywords: dental bonding; composite resins; methacrylates; silorane resins; polymerization.

\section{Introduction}

Polymerization of methacrylate-based composite is characterized by volumetric shrinkage ${ }^{1}$. These photo-activated restorative materials exhibit a significant proportion of methacrylate groups unreacted due to an incomplete conversion of carbon double bonds ${ }^{2}$. However, the higher the degree of conversion (DC), the higher the shrinkage strain $^{3}$. Polymerization stress may result in cuspal deflection $^{4}$, de-bonding at composite-dentin interface, post-operative sensitivity ${ }^{5-6}$, microleakage ${ }^{5}$, secondary caries formation, marginal staining, restoration and dental fractures ${ }^{6}$, all reducing the longevity of the restoration.

Recently a low shrinkage monomer was developed from the reaction of the oxirane and siloxane molecules, termed silorane ${ }^{4,7}$. Silorane presents a cationic ring-opening polymerization mechanism instead of the free radical cure of methacrylate monomers ${ }^{4}$ and an exended light-curing time to form cations is necessary to initiate the polymerization reaction ${ }^{1,4}$. It exhibits lower polymerization shrinkage $e^{4,8}$ and mechanical properties comparable to that of methacrylate dental composites ${ }^{7}$. 
In deep cavity the irradiance that reaches the restorative material surface is decreased by the distance between the guide tip of the light-curing unit and material during the restorative procedure, reducing the degree of conversion, and/or leading to the formation of more polymers with linear structures, presenting inferior physical properties and will result in the weakening of the restoration ${ }^{9}$.

Improvement of the physical properties of resin-based materials with increase of the curing time available for the conversion of monomers to polymers has been reported ${ }^{3,10-11}$. However, few studies have assessed the bond strength of this new restorative system with different light-curing times and after aging. Therefore, the objective of this study was to evaluate the influence of different restorative systems and curing times on the microtensile bond strength (microTBS) after $24 \mathrm{~h}$ and 6 months. The research hypotheses tested were that: (1) there would be no difference between restorative systems, (2) extended light-curing time would increase bond strength, and (3) aging would decrease microTBS values.

\section{Material and methods}

This study was approved by the Institutional Review Board under protocol number 031/2010. Fifty-six freshly extracted non-carious, unrestored human third molars were collected and stored in $0.1 \%$ thymol solution at $4{ }^{\circ} \mathrm{C}$. The teeth were scaled, cleaned, stored in distilled water at $4{ }^{\circ} \mathrm{C}$, and used within 3 months after extraction.

The toot roots were embedded in polystyrene resin (Piraglass, Piracicaba, SP, Brazil) to facilitate the handling, and the occlusal surfaces were ground wet onto 320-grit SiC paper in a polishing machine (APL-4, Arotec, São Paulo, SP, Brazil) until the distance between the occlusal surface and cementum-enamel junction was $5 \mathrm{~mm}$. Standardized Class II vertical slot preparations were performed on one of the proximal surfaces of human molars with regular-grit cylindrical diamond bur (no. 3100; KG Sorensen, Barueri, SP, Brazil) using a high speed handpiece with water spray coolant. Cavity dimensions were $4 \mathrm{~mm}$ wide, $6 \mathrm{~mm}$ high (1 $\mathrm{mm}$ below the cementoenamel junction), and $2 \mathrm{~mm}$ of axial depth (from the proximal surface to the axial wall). A custommade preparation device allowed the standardization of the preparations dimensions. The margins were not beveled and burs were replaced after five preparations.

Table 1 shows the information about the materials used in this study. Methacrylate- [Clearfil SE Bond (Kuraray Medical Inc. Okayama, Japan) + Filtek Z250 (3M ESPE, St. Paul, MN, USA)] and silorane-based [Filtek LS system (3M ESPE)] restorative systems were used in the restorative procedures. The cavities were sequentially randomized in 8 groups $(\mathrm{n}=7)$ (Table 2$)$, and the following restorative protocols were accomplished: for the methacrylate groups (1, 2, 5, and 6), Clearfil SE Bond primer (bottle A) was vigorously scrubbed with applicator brushes in the entire cavity during $20 \mathrm{~s}$, a mild air stream was applied for solvent evaporation, the bonding agent (bottle B) was applied, gently air thinned and light-cured for $10 \mathrm{~s} \mathrm{(G1} \mathrm{and} \mathrm{G5)} \mathrm{or} 20 \mathrm{~s}$ (G2 and G6). For silorane groups (3, 4, 7, and 8), Filtek LS primer (bottle 1) was actively applied for $15 \mathrm{~s}$, gently air thinned, light cured for $10 \mathrm{~s}$ (G3 and G7) or $20 \mathrm{~s}$ (G4 and G8), and the bonding agent (bottle 2) was applied, thinned with a gentle air stream and light-cured for 10 or $20 \mathrm{~s}$. After bonding procedures, individual transparent matrices were placed to allow the adequate filling of the proximal preparation. Three approximately 2 -mm-thick horizontal composite resin increments were inserted, measured with a millimeter periodontal probe with Williams' markings (Golgran, São Paulo, SP, Brazil) positioned parallel to the tooth proximal surface, and light-cured for 20 or $40 \mathrm{~s}$ (Table 2).

The resin materials were light-cured at the occlusal surface using a second-generation light-emitting diode (LED) unit (Bluephase 16i; Ivoclar Vivadent, Amherst, NY, USA) device at $1390 \mathrm{~mW} / \mathrm{cm}^{2}$ of output irradiance (at $0 \mathrm{~mm}$ ). The optical power $(\mathrm{mW})$ delivered by the device was measured with a power meter (Ophir Optronics, Har Hotzvim, Jerusalem, Israel). The tip diameter was measured with a digital caliper (Mitutoyo Sul Americana, Suzano, SP, Brazil); recorded 7 $\mathrm{mm}$ and tip area was determined in $\mathrm{cm}^{2}$. Irradiance $(\mathrm{mW} /$ $\mathrm{cm}^{2}$ ) was calculated dividing light power by tip area. The

Table 1. Materials used in this study.

\begin{tabular}{ll}
\hline Material & \multicolumn{1}{c}{ Composition* } \\
Clearfil SE Bond(Kuraray Medical & Lot. 00955A PrimerMDP, HEMA, water, CQ, hydrophilic dimethacrylate.Lot. 01416A BondMDP, Bis-GMA, HEMA, CQ, \\
Inc. Okayama, Japan) & hydrophobic dimethacrylate, N,N-diethanol p-toluidine, colloidal silica.
\end{tabular}

Filtek LS adhesive(3M ESPE, Seefeld, Germany)

Filtek Z250(A2 shade; 3M ESPE, St. Paul, MN, USA)

Filtek LS composite(A2 shade; 3M ESPE, St. Paul, MN, USA)

${ }^{*}$ As informed by manufacturers.

Abbreviations - MDP: 10-methacryloyloxydecyl dihydrogen phosphate; HEMA: 2-hydroxyethylmethacrylate; CQ: camphorquinone; Bis-GMA: bisphenol-A glycidyl dimethacrylate; TEGDMA: triethylene glycol dimethacrylate; Bis-EMA: ethoxylated bisphenol-A dimethacrylate; and UDMA: urethane dimethacrylate.
Lot. 9BN PrimerBis-GMA, HEMA, water, ethanol, silica treated silica filler, CQ, phosphoric acid-methacryloxy-hexylesters mixture, phosphorylated methacrylates, copolymer of acryl and itaconic acid, phosphine oxide.Lot. 9BK BondHydrophobic dimethacrylate, phosphorylated methacrylates, TEGDMA, silane treated silica, CQ, stabilizers. 
Table 2. Experimental groups.

\begin{tabular}{llll}
\hline Group & Restorative system & Light-curing time* & Water storage \\
G1 & Methacrylate & Recommended by the manufacturers & $24 \mathrm{~h}$ \\
G2 & Methacrylate & Double time & $24 \mathrm{~h}$ \\
G3 & Silorane & Recommended by the manufacturer & $24 \mathrm{~h}$ \\
G4 & Silorane & Double time & $24 \mathrm{~h}$ \\
G5 & Methacrylate & Recommended by the manufacturers & 6 months \\
G6 & Methacrylate & Double time & 6 months \\
G7 & Silorane & Recommended by the manufacturer & 6 months \\
G8 & Silorane & Double time & 6 months \\
\hline${ }^{*}$ Manufacturer's recommendation or double the recommended time: adhesive system (10 or 20 s) and composite \\
resin $(20$ or 40 s).
\end{tabular}

irradiances also were calculated positioning a spacer device (with heights of 4 and $6 \mathrm{~mm}$ ) between the light guide tip of the curing unit and the surface of the power meter, and beneath resin disks for both composites made using a standardized Teflon matrix (with $2 \mathrm{~mm}$ of thickness, simulating the first increment) at $4 \mathrm{~mm}$ of the top surface of resin disk. The distance between the light guide tip and the bottom of cavity was $6 \mathrm{~mm}$ with an irradiance of $610 \mathrm{~mW} / \mathrm{cm}^{2}$, when the adhesive systems were cured. The composite increment was approximately $2 \mathrm{~mm}$ thick, totalizing $990 \mathrm{~mW} / \mathrm{cm}^{2}$ on the top surface of the first composite increment at $4 \mathrm{~mm}$ of distance between light guide tip and top surface of the first composite increment. The irradiance on the bottom surface at $6 \mathrm{~mm}$ (beneath both 2-mm-thick composite resin disks) was $380 \pm 5 \mathrm{~mW} / \mathrm{cm}^{2}$.

After restorative procedures, specimens were stored in distilled water at $37{ }^{\circ} \mathrm{C}$ for $24 \mathrm{~h}$. After this period, the proximal surface was finished and polished with $\mathrm{Al}_{2} \mathrm{O}_{3}$ abrasive discs (Sof-Lex Pop-On, 3M ESPE), from coarse to superfine for $30 \mathrm{~s}$ with a rotating hand piece at approximately $10,000 \mathrm{rpm}$. Then, the restored teeth were serially sectioned to yield 3 series of $0.8 \mathrm{~mm}$ thick vertical slices using a diamond saw (Isomet 1000; Buehler, Lake Bluff, IL, USA) at $300 \mathrm{rpm}$. Each slab was trimmed into an hourglass shape of approximately $0.64 \mathrm{~mm}^{2}$ area at the gingival resin-dentin interface using a super-fine diamond bur (no. 1090FF; KG Sorensen). In the aged groups (G5-G8, Table 2), the hourglasses were stored in distilled water at 37 ${ }^{\circ} \mathrm{C}$ for 6 months, changed weekly. All specimens had direct exposure to storage fluid ${ }^{12}$. This procedure is commonly used and considered a type of accelerated aging ${ }^{13}$.

Twenty-four hours or 6 months after water storage at 37 ${ }^{\circ} \mathrm{C}$, the cross-sectional area of each hourglass was measured with a digital caliper to the nearest $0.01 \mathrm{~mm}$ and recorded for the calculation of the dentin bond strength. Each bonded slab was individually attached to a flat grip Geraldeli device for microtensile testing with cyanoacrylate instant adhesive (Super Bonder Gel; Loctite-Henkel, São Paulo, SP, Brazil), and subjected to a tensile force using a universal testing machine (DL 500; EMIC, São José dos Pinhas, PR, Brazil) at crosshead speed of $0.5 \mathrm{~mm} / \mathrm{min}$ until failure. The number of slabs prematurely de-bonded during specimen preparation was recorded, but no bond strength value was attributed for statistical analysis ${ }^{14}$. The bond strength values obtained from the 3 slices of each tooth were used to calculate the microTBS of the specimen. Means and standard deviations were calculated and expressed in Mega Pascals (MPa).

After microTBS test, the dentin side of the fractured specimens was dried by silica stored in incubator at $37{ }^{\circ} \mathrm{C}$ for $48 \mathrm{~h}$, mounted on the aluminum stubs, and gold sputtercoated under high vacuum (SCD 050; BAL-TEC AG, Balzers, Liechtenstein). A scanning electron microscope (SEM; JSM $5600 \mathrm{LV}$, JEOL, Tokyo, Japan) was used to evaluate the bond failure modes of the fractured specimens on the dentin side with magnifications between 70 and $1000 \mathrm{X}$ and classified as follows: (1) cohesive in dentin, (2) adhesive, (3) cohesive in the composite, and (4) mixed. The microTBS data obtained by to assume the normality presuppositions were analyzed by three-way ANOVA and Tukey's test at a 0.05 level of significance. The main factors were restorative system, curing and storage times.

\section{Results}

The methacrylate-based restorative system showed higher dentin bond strength than the silorane-based material $(p<0.001)$, the extended light-curing time resulted in higher microTBS values $(p=0.0034)$ and there was no statistically significant difference between $24 \mathrm{~h}$ and 6 months $(\mathrm{p}>0.05)$ (Table 3).

The descriptive analysis of failure modes and the number of pre-testing failures for each experimental group are shown in Table 4.

\section{Discussion}

The first hypothesis tested was rejected, since the methacrylate materials presented greater dentin bond

Table 3. Microtensile bond strength values [MPa (S.D.)] according to restorative system, aging, and curing time.

\begin{tabular}{llll}
\multicolumn{2}{l}{ Restorative system } & \multicolumn{2}{c}{ Light-curing time } \\
\multirow{2}{*}{ Methacrylate } & $24 \mathrm{~h}$ & $* 28.01(4.21) \mathrm{Aa}$ & $* 30.68(4.89) \mathrm{Ba}$ \\
\multirow{3}{*}{ Silorane } & 6 months & $* 23.84(3.91) \mathrm{Aa}$ & $* 28.15(4.81) \mathrm{Ba}$ \\
& $24 \mathrm{~h}$ & $17.18(3.86) \mathrm{Aa}$ & $20.06(3.31) \mathrm{Ba}$ \\
& 6 months & $16.93(3.20) \mathrm{Aa}$ & $20.37(3.71) \mathrm{Ba}$
\end{tabular}

Distinct letters (capital in the rows and lowercase in the columns) are statistically different $(p \leq 0.05)$. "Differs from the silorane restorative system $(p<0.001)$. The longer light-curing time promoted greater bond strength $(p=0.0034)$. There was no statistically significant difference for aging $(p>0.05)$. 
Table 4. Fracture pattern analysis

\begin{tabular}{cccccc}
\hline & & \multicolumn{4}{c}{ Failure modes (\%) } \\
\cline { 3 - 6 } Group & $\begin{array}{c}\text { Pre- } \\
\text { testing } \\
\text { failure }\end{array}$ & $\begin{array}{c}\text { Cohesive } \\
\text { in the } \\
\text { dentin }\end{array}$ & Adhesive & $\begin{array}{c}\text { Cohesive } \\
\text { in the } \\
\text { composite }\end{array}$ & Mixed \\
G1 & $3 / 21$ & - & 76.47 & - & 23.53 \\
G2 & $0 / 21$ & - & 42.86 & - & 57.14 \\
G3 & $3 / 21$ & - & 16.67 & - & 83.33 \\
G4 & $2 / 21$ & - & 26.32 & - & 73.68 \\
G5 & $3 / 21$ & - & 88.24 & - & 11.76 \\
G6 & $2 / 21$ & - & 61.11 & - & 38.89 \\
G7 & $3 / 21$ & - & 27.78 & - & 72.22 \\
G8 & $1 / 21$ & - & 30.00 & - & 70.00 \\
\hline
\end{tabular}

strength than the low shrinkage restorative system (Table 3 ), in accordance with a previous study that showed higher microTBS for methacrylate than silorane composite regardless of placement technique ${ }^{15}$. Self-etch adhesives are based on absence of rinsing and drying steps, maintaining the ideal dentinal humidity and reducing technique sensitivity ${ }^{13}$. Twostep self-etch adhesive consists in a self-etch primer with acid monomers that demineralize and simultaneously penetrate monomers into dentin subsurface, followed by application of a solvent-free hydrophobic bond agent, which provides better mechanical properties ${ }^{16}$.

All-in-one adhesive contains a mixture of acid, hydrophilic, and hydrophobic monomers, water and organic solvents in a single bottle ${ }^{16}$. This adhesive is more hydrophilic, allowing deeper penetration with water content increases due to adhesive acidification in water presence, interfering on polymerization, which leads to uncured acid and aggressive monomers that continue etching the dentin, affecting negatively the bonding interface ${ }^{16-17}$. Most one-step self-etch adhesives are severely affected by the hydrolytic degradation ${ }^{18}$. However, longevity over time was not related to the number of steps of the bonding systems, but to their chemical compositions ${ }^{19}$.

Clearfil SE Bond consists in a hydrophilic self-etch primer and hydrophobic bond agent. This viscous hydrophobic resin-coating layer improves mechanical properties and increases longevity of the bonding interface ${ }^{16}$. Filtek LS low shrinkage composite resin has a dedicated self-etching adhesive. Although LS Adhesive System is classified by the manufacturer as a two-step self-etch adhesive, the hydrophilic LS primer is applied first and then lightcured forming the hybrid layer ${ }^{1}$. Thus, the bifunctional hydrophobic monomer (phosphorylated methacrylate) of the LS bond applied after the primer cured acts as a low viscosity composite connection liner between methacrylate monomers (by reaction with acrylate group) and silorane monomer (by reaction of the phosphate group with oxirane $)^{8}$. Therefore, LS primer is a one-step self-etch adhesive, which could explain the lower bond strength values ${ }^{1}$.

The mild self-etch primer of Clearfil SE Bond has a $\mathrm{pH}$ of $2.0^{16}$, and is composed by a functional acid monomer MDP, which adheres to the tooth hydroxyapatite most readily and intensely ${ }^{20}$. This stable chemical bond was left around the collagen fibrils within the hybrid layer ${ }^{21}$. The self-etch LS primer has a $\mathrm{pH}$ of $2.7^{6}$ and is classified as ultra-mild ${ }^{1,6,21}$. Transmission electron microscopy (TEM) of LS adhesive shows a thin nano-interaction zone, which is probably the combination of the resin-impregnation within smear layer and actual hybridized dentin ${ }^{1,6}$. Smear debris interfere in the interaction between the mild and ultra-mild self-etching adhesives with dentin tissue ${ }^{22}$. The bonding effectiveness of ultra-mild one-step self-etch adhesive is largely affected by the properties of the produced smear layer because it interacts superficially with the smear layer-covered dentin ${ }^{23}$. It has been reported that two-step self-etch adhesive systems performed better at bonding ability than one-step self-etch adhesives $^{13,19,21}$.

A longer light-curing time increased the microTBS of the tested restorative systems (Table 3); therefore, the second hypothesis was validated. It is now that only $1 \mathrm{~mm}$ distance increase between the light guide tip and restorative material decreases the light intensity by approximately $10 \%{ }^{24}$. Several studies have related the improvement of the physical properties of resin-based materials with increase of the curing time, due to the higher $\mathrm{DC}^{3,10-11}$. There is a significant correlation between bond strength and total curing time $\mathrm{e}^{25}$ with greater $\mathrm{DC}^{26}$. Special care should be taken when performing the polymerization of resinous materials with lower light power curing units at deep cavities.

The onset of cationic ring-opening polymerization of the silorane is slower due to the required formation of sufficient cations to initiate polymerization, thus a longer light-curing time is required compared with radical cure of methacrylate monomer molecules into polymer network ${ }^{1,4}$. The curing device used in this investigation consists in single peak second generation LED. This unit presents a high optical power and spectrum between 410 and $530 \mathrm{~nm}$ with a peak on at $454 \mathrm{~nm}$ that includes the maximum energy absorption peak of the camphorquinone at $(468 \mathrm{~nm})^{27}$, the photo-initiator included in all tested resin-based materials.

The light-curing time recommended for silorane composite using quartz-tungsten-halogen (QTH) with irradiance between $500-1400 \mathrm{~mW} / \mathrm{cm}^{2}$ is $40 \mathrm{~s}$, as well as for LEDs with output between $500-1000 \mathrm{~mW} / \mathrm{cm}^{2}$. For LEDs with irradiance between $1000-1500 \mathrm{~mW} / \mathrm{cm}^{2}$ is advised an exposure light time of $20 \mathrm{~s}$. An irradiation of $10 \mathrm{~s}$ is recommended to cure the primer and bond of LS Adhesive, without concern about minimum irradiance. In this study it was used a LED with irradiance of $1390 \mathrm{~mW} / \mathrm{cm}^{2}$, indicating 20 and 10 s of light polymerization for composite and adhesive, respectively. However, the irradiance achieved on the surface of the first composite increment was of $990 \mathrm{~mW} /$ $\mathrm{cm}^{2}$ at $4 \mathrm{~mm}$ of tip, and on the adhesive system was of 610 $\mathrm{mW} / \mathrm{cm}^{2}$ at $6 \mathrm{~mm}$ (applied on cavity bottom) of light guide tip. Furthermore, at a $4 \mathrm{~mm}$ distance from the light guide tip to the top surface of the composite and curing beneath the restorative material, the irradiance at the bottom surface was $380 \mathrm{~mW} / \mathrm{cm}^{2}$. Bond strength is influenced by monomer conversion ${ }^{26}$; thus, extended curing time may have increased 
the DC of adhesives ${ }^{11}$ and/or composites, and improved the dentin microTBS.

The third hypothesis was rejected because the long-term water storage did not affect the bond interface of the restorations (Table 3). Interface components can be degraded by hydrolysis and water may infiltrate, resulting in the plasticization of the polymeric matrix, by swelling and reduction of the frictional forces between the polymer chains, reducing the mechanical properties, and consequently the bonding interface integrity ${ }^{13}$. However, the 6 months of water storage did not decrease the microTBS values, similar result as reported elsewhere ${ }^{5}$. On the other hand, other studies showed a significant decrease in the bond strength after shorter periods (within 3 months) ${ }^{28}$, and even after longer periods (within 4 years) $)^{25}$.

The MDP-contained Clearfil SE Bond adhesive system in contact with the tooth forms the MDP-calcium salt that hardly dissolved in water. Therefore the bond between MDP and hydroxyapatite should be stable $^{20}$. Thus, the chemical interaction improves the resistance to hydrolytic breakdown and de-bonding stress, keeping the restoration margins sealed for longer periods ${ }^{21}$. Moreover, since primer application followed by the hydrophobic bonding agent contained mainly cross-linking monomers, Clearfil's bond provides better mechanical properties to Clearfil ${ }^{16}$. This fact, combined with methacrylate Filtek Z250 composite and high power density, could result in the long-term stability of the bond interface.

Single-bottle adhesives such as the one-step self-etch LS primer may act as permeable membranes and be more susceptible to aging ${ }^{29}$. Moreover, these adhesives are strongly influenced by light intensity of the photo-curing device ${ }^{16}$. Thus the second viscous hydrophobic coating layer (LS bond) seems to have improved the vulnerability to water sorption resultant of the high HEMA content in the LS primer, applied and cured previously ${ }^{6}$, after long-term water storage. Additionally, the active application of one-step self-etch adhesives has been related to improvement in the bonding performance ${ }^{30}$, along with the increased hydrophobicity of the silorane composite resin due to the presence of siloxane species ${ }^{7}$. The high irradiance could also contribute to the bond longevity of this new restorative system.

The methacrylate restorative system showed more adhesive failures, while silorane exhibited more mixed failures (Table 4). Most silorane fractures occurred between the bonding agent and the composite, with part of the bonding remaining on dentin surface as well, perhaps due to the lower adhesion compared to adhesion between the methacrylatebased materials. The longer irradiation time increased the occurrence of mixed failures and decreased the adhesive failures for methacrylate restorative system, likely by greater monomeric conversion. Water storage increased the adhesive failures percentage for both restorative systems, probably by swelling of the polymer network and reduction of the frictional forces between polymeric chains.

The quality and uniformity of the polymerization reaction is an important parameter that affects the conversion of the monomers into structured polymers, and therefore improves the physical properties and clinical performance; however, this process is dependent of various factors, such as design and size of the tip guide, distance of the light guide tip from the material surface, power density, exposure duration, shade and opacity of the composite, increment thickness, materials' composition, and others9. Thus, manufacturers should provide information, such as minimum irradiance and time of light curing required for optimal polymerization of their adhesive systems ${ }^{27}$, and make clear, in their instructions of use, that the minimum irradiance indicated is the one that reaches the surface of the material and not the optical power of output of the light-curing device. Higher irradiance is necessary to adequately cure photoactivated materials in deep cavities, and contribute to the improvement of the longevity of adhesive dental restorations.

The longer light-curing time improved the bond strength for both restorative materials and the groups restored with LS restorative system showed the lowest dentin microTBS values; however, long-term storage after 6 months in distilled water did not affect the bond durability of the tested restorations.

\section{Acknowledgements}

This study was supported by the FAPESP (Grants: 2010/ 05666-9 and 2010/15076-4).

\section{References}

1. Van Ende A, De Munck J, Mine A, Lambrechts P, Van Meerbeek B. Does a low-shrinking composite induce less stress at the adhesive interface? Dent Mater. 2010; 26: 215-22.

2. Asmussen $E$, PeutzfeldtA. Influence of selected components on crosslink density in polymer structures. Eur J Oral Sci. 2001; 109: 282-5.

3. Yap AU, Seneviratne C. Influence of light density on effectiveness of composite cure. Oper Dent. 2001; 26: 460-6.

4. Palin WM, Fleming GJ, Nathwani H, Burke FJ, Randall RC. In vitro cuspal deflection and microleakage of maxillary premolars restored with novel low-shrink dental composites. Dent Mater. 2005; 21: 324-35.

5. Duarte S Jr, Phark JH, Varjão FM, Sadan A. Nanoleakage, ultramorphological characteristics, and microtensile bond strengths of a new low-shrinkage composite to dentin after artificial aging. Dent Mater. 2009; 25: 589-600.

6. Mine A, De Munck J, Van Ende A, Cardoso MV, Kuboki T, Yoshida Y, et al. TEM characterization of a silorane composite bonded to enamel/dentin. Dent Mater. 2010; 26: 524-32.

7. Ilie N, Hickel R. Silorane-based dental composite: behavior and abilities. Dent Mater J. 2006; 25: 445-54.

8. Tezvergil-Mutluay A, Lassila LV, Vallittu PK. Incremental layers bonding of silorane composite: the initial bonding properties. J Dent. 2008; 36: 560-3.

9. Aguiar FH, Lazzari CR, Lima DA, Ambrosano GM, Lovadino JR. Effect of light curing tip distance and resin shade on microhardness of a hybrid resin composite. Braz Oral Res. 2005; 19: 302-6.

10. Borges BC, Souza-Junior EJ, Catelan A, Ambrosano GM, Paulillo LA, Aguiar FH. Impact of extended radiant exposure time on polymerization depth of fluoride-containing fissure sealer materials. Acta Odontol Latinoam. 2011; 24: 47-51.

11. Catelan A, Ambrosano GM, Lima DA, Marchi GM, Aguiar FH. Influence of radiant exposure on degree of conversion, water sorption and solubility of self-etch adhesives. Int J Adhes Adhes. 2013; 46: 40-3. 
12. Toledano M, Osorio R, Osorio E, Aguilera FS, Yamauti M, Pashley DH, et al. Durability of resin-dentin bonds: effects of direct/indirect exposure and storage media. Dent Mater. 2007; 23: 885-92.

13. De Munck J, Van Landuyt K, Peumans M, Poitevin A, Lambrechts P, Braem $M$, et al. A critical review of the durability of adhesion to tooth tissue: methods and results. J Dent Res. 2005; 84: 118-32.

14. Cabrera E, Macorra JC. Microtensile bond strength distributions of three composite materials with different polymerization shrinkages bonded to dentin. J Adhes Dent. 2011; 13: 39-48.

15. Almeida e Silva JS, Rolla JN, Baratieri LN, Monteiro S Jr. The influence of different placement techniques on the microtensile bond strength of lowshrink silorane composite bonded to Class I cavities. Gen Dent. 2011; 59 : e233-7.

16. Seki N, Nakajima M, Kishikawa R, Hosaka K, Foxton RM, Tagami J. The influence of light intensities irradiated directly and indirectly through resin composite to self-etch adhesives on dentin bonding. Dent Mater $\mathrm{J}$. 2011; 30: 315-22.

17. Vanajasan PP, Dhakshinamoorthy M, Rao CS. Factors affecting the bond strength of self-etch adhesives: a meta-analysis of literature. J Conserv Dent. 2011; 14: 62-7.

18. Walter R, Swift EJ Jr, Nagaoka H, Chung Y, Bartholomew W, Braswell KM et al. Two-year bond strengths of "all-in-one" adhesives to dentine. J Dent. 2012; 40: 549-55.

19. Marchesi G, Frassetto A, Visintini E, Diolosà M, Turco G, Salgarello $S$, et al. Influence of ageing on self-etch adhesives: one-step vs. two-step systems. Eur J Oral Sci. 2013; 121: 43-9.

20. Yoshida Y, Nagakane K, Fukuda R, Nakayama Y, Okazaki M, Shintani $\mathrm{H}$, et al. Comparative study on adhesive performance of functional monomers. J Dent Res. 2004; 83: 454-8.

21. Sarr M, Kane AW, Vreven J, Mine A, Van Landuyt KL, Peumans M, et al. Microtensile bond strength and interfacial characterization of 11 contemporary adhesives bonded to bur-cut dentin. Oper Dent. 2010; 35: 94-104.

22. Suyama Y, Lührs AK, De Munck J, Mine A, Poitevin A, Yamada T, et al. Potential smear layer interference with bonding of self-etching adhesives to dentin. J Adhes Dent. 2013; 15: 317-24.

23. Ermis RB, De Munck J, Cardoso MV, Coutinho E, Van Landuyt KL, Poitevin $A$, et al. Bond strength of self-etch adhesives to dentin prepared with three different diamond burs. Dent Mater. 2008; 24: 978-85.

24. Prati C, Chersoni S, Montebugnoli L, Montanari G. Effect of air, dentin and resin-based composite thickness on light intensity reduction. Am J Dent. 1999; 12: 231-4.

25. AbdallaAl, Feilzer AJ. Four-year water degradation of a total-etch and two self-etching adhesives bonded to dentin. J Dent. 2008; 36: 611-7.

26. Oguri M, Yoshida Y, Yoshihara K, Miyauchi T, Nakamura Y, Shimoda S, et al. Effects of functional monomers and photo-initiators on the degree of conversion of a dental adhesive. Acta Biomater. 2012; 8: 1928-34.

27. Faria-e-Silva AL, Lima AF, Moraes RR, Piva E, Martins LR. Degree of conversion of etch-and-rinse and self-etch adhesives light-cured using QTH or LED. Oper Dent. 2010; 35: 649-54.

28. Krajangta N, Srisawasdi S. Microtensile bond strength of silorane-based resin composite and its corresponding adhesive in Class I occlusal restorations. Am J Dent. 2011; 24: 346-53.

29. Tay FR, Pashley DH, Peters MC. Adhesive permeability affects composite coupling to dentin treated with a self-etch adhesive. Oper Dent. 2003; 28 : 610-21.

30. do Amaral RC, Stanislawczuk R, Zander-Grande C, Michel MD, Reis A, Loguercio AD. Active application improves the bonding performance of self-etch adhesives to dentin. J Dent. 2009; 37: 82-9. 